Friedrich Breyer / Martin Kolmar

\title{
Grundlagen der Wirtschaftspolitik
}

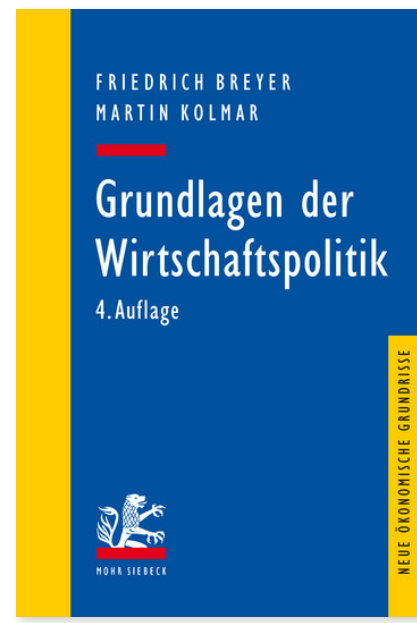

4., überarbeitete Auflage; 2014. XII, 408 Seiten. NöG

ISBN 978-3-16-153206-1

DOI 10.1628/978-3-16-153206-1

eBook PDF $34,00 €$

ISBN 978-3-16-153205-4

fadengeheftete Broschur $34,00 €$
Die vorliegende 4. Auflage wurde grundlegend überarbeitet und ergänzt.

"Leser werden die zahlreichen Fallbeispiele und Übungsaufgaben zu schätzen wissen, mit denen der Text gespickt ist. Sie stellen den Bezug zur Praxis her, helfen bei der Aufnahme des Lernstoffs - und verstärken damit den rundum positiven Gesamteindruck.«

Studium 2010, Ausgabe 86, S. $26 f$

Für Bibliotheken gelten bei diesem Titel abweichende Konditionen; bitte wenden Sie sich an den Vertrieb.

Inhaltsübersicht

Teil I: Grundlagen

1. Einführung

2. Theorien der Gerechtigkeit

3. Staat, Eigentum, Effizienz

Teil II: Perfekte Steuerbarkeit

4. Allokationsprobleme

5. Rivalisierende Güter

6. Nichtrivalisierende Güter

7. Zunehmende Skalenerträge in der Produktion

Teil III: Imperfekte Steuerbarkeit

8. Abweichung vom Prinzip der vollständigen Internationalisierung

9. Positionsgüter in einer Marktwirtschaft

10. Asymmetrische Informationen

11. Imperfekt durchgesetzte Eigentumsordnungen

Friedrich Breyer Geboren 1950; Studium der Volkswirtschaftslehre; 1978 Promotion; 1983 Habilitation; seit 1992 Ordinarius für Wirtschaftspolitik an der Universität Konstanz.

Martin Kolmar Geboren 1967; Studium der Volkswirtschaftslehre; 1997 Promotion; 2002 Habilitation; seit 2006 Professor für Angewandte Mikroökonomik an der Universität St. Gallen und Direktor des Instituts für Finanzwissenschaft und Finanzrecht.

Jetzt bestellen:

https://mohrsiebeck.com/buch/grundlagen-der-wirtschaftspolitik-9783161532061?no_cache=1

order@mohrsiebeck.com

Telefon: +49 (0)7071-923-17

Telefax: +49(0)7071-51104 